\title{
Life cycle of a torrenticolous Hawaiian chironomid (Telmatogeton torrenticola) : stream flow and microhabitat effects
}

\author{
M.E. Benbow ${ }^{1,3}$, A.J. Burky1, C.M. Way² \\ ${ }^{1}$ Department of Biology, University of Dayton, Dayton, OH 45469-2320, USA. \\ 2 Barry Vittor and Associates, Inc., 8060 Cottage Hill Rd., Mobile, AL 36695, East Lansing, MI, 48824-1115, USA
}

\begin{abstract}
In this study we documented the instar densities and life cycle of Telmatogeton torrenticola Terry (Chironomidae : Telmatogetoninae) from Kinihapai Stream, Maui, Hawaii. Greatest larval densities of this midge are found on substrates of high velocity, shallow flows of cascades, and splash zones of waterfalls, with lower densities in riffles. In the summer of 1994 we compared the effects of two microhabitats (termed optimal and suboptimal) on inter-instar density and relative abundance. In a second year (1995), we evaluated the effect of long-term reduced stream flow on these variables only in optimal microhabitats. A significant reduction in stream flow from 1994 to 1995 was correlated with a similar reduction in larval densities that precluded larval colonization of suboptimal habitats in 1995, thereby preventing sampling in this microhabitat during that summer. Depth of optimal habitats of 1995 were significantly shallower than both habitats of 1994, with suboptimal habitats of 1994 the deepest. Total larval density was significantly higher in 1994 optimal habitats, while 1994 suboptimal and 1995 optimal habitats were statistically similar. Individual instar densities showed variable differences among habitats and years, with the first three instars always highest in 1994 optimal habitats. All instars and pupae were collected on most sampling dates in both years ; however, pupae were only collected on a two dates in suboptimal habitats of 1994. Based on larval size frequency histograms, T. torrenticola has a multivoltine, asynchronous life cycle, with continuous reproduction, which is variable among microhabitats characterized by different flow velocity and depth, and between years of differing stream discharge. Reduced stream flow during the summer of 1995 had effects of reducing densities and changing life cycle features similar to those found in 1994 (a year of higher stream flow) suboptimal habitats.
\end{abstract}

Keywords : Chironomidae, Telmatogeton torrenticola, tropical, torrenticolous, life cycle, phenology, stream flow.

\section{Introduction}

Freshwater studies of Hawaiian stream fauna have been historically focused on the amphidromous fish (Zink et al. 1996, Chubb et al. 1998), while aquatic insect studies have been largely limited to taxonomic descriptions and reports of species distributions and exotic introductions (Williams 1944, Wirth 1947, Englund 2002). While the enormous contributions of

\footnotetext{
3 Present \& Corresponding Address : Department of Entomology, Michigan State University, East Lansing, MI 48824-1115, USA. Email : benbow@msu.edu
}

R.C.L. Perkins (reviewed in Liebherr \& Polhemus 1997) and Elwood Zimmerman's Insects of Hawaii (Zimmerman 2001, Vol. 1 reissue) provide extensive insect taxonomy, both only briefly note on the ecology and biology of Hawaiian insects. Besides a few recent ecological papers (see below), there has been relatively little published on Hawaiian larval aquatic insect ecology when compared to studies from mainland lotic systems. More studies of tropical stream insects are needed for a more global knowledge base in aquatic entomology (Jackson \& Sweeney 1995).

The paucity of Hawaiian aquatic larval insect ecological publications was interrupted by a study by Kondratieff et al. (1997), that documented the life cycle of an introduced caddisfly, Cheumatopsyche pettiti 
Banks, while Benbow et al. (1997) published data on the habitat preferences of the endemic midge of this study, Telmatogeton torrenticola Terry (Diptera : Chironomidae : Telmatogetoninae). More recently, a study by McIntosh et al. (2002) addressed the effects of reduced flow on stream macroinvertebrates, while Englund and Polhemus (2001) evaluated the effects of rainbow trout on native stream insect assemblages of Kauai. Wolff et al. (2002) documented new state records of Hawaiian Chironomidae, but there was no quantitative information presented. Beyond several studies providing island distribution, phylogeny and habitat characteristics of the Megalagrion complex (Polhemus \& Asquith 1996 ; Polhemus 1997, Englund 1998, Englund 1999), there have been few other published studies providing quantitative, ecological data on other aquatic insect groups (e.g., Diptera).

Because of this lag of ecological information, we conducted several studies addressing the ecological dynamics of Hawaiian stream insect assemblages (Benbow 1999). One of these studies focused on T. torrenticola, found only on the islands of Hawai'i, Maui, and Moloka'i (Williams 1944). There have been three studies addressing the evolutionary relationships of the freshwater Telmatogeton species and their marine relatives of Hawai'i (Tokunaga 1935, Newman 1977, Newman 1988), while only short descriptions of taxonomy and habitat provided limited ecological data (Williams 1944, Wirth 1947). This species complex is unique, with the five Hawaiian freshwater Telmatogeton species as the only freshwater representatives of the genus, reflecting a reinvasion of freshwater from a marine ancestor (Wirth 1947, Newman 1977, Newman 1988). Further, the marine species of this genus are found throughout the world in intertidal habitats (Cranston 1995), and the freshwater Hawaiian Telmatogeton are found primarily in torrenticolous microhabitats, a unique and uncommon microhabitat for chironomids. In a previous study (Benbow et al. 1997), we quantified the micro-scale flow and depth habitat of $T$. torrenticola, but to our knowledge there are no other published, quantitative studies on the biology or ecology of any Hawaiian freshwater Telmatogeton species.

The objectives of this study were to quantitatively describe the larval densities and life cycle characteristics (e.g., relative instar abundance and voltinism) of $T$. torrenticola in microhabitats between two summers of significantly different mean daily discharge. Our null hypothesis was that larval density and life cycle characteristics would not change significantly between years or microhabitats of differing flow.

\section{Methods and materials}

\section{Study site}

This study was conducted on the island of Maui, Hawaii, in Kinihapai Stream at Iao Valley State Park $\left(20^{\circ}\right.$ 53' $08^{\prime \prime} \mathrm{N} ; 156^{\circ} 32^{\prime} 32^{\prime} \mathrm{W}$ ). Kinihapai Stream is a steep, first order tributary of Iao Stream $\sim 1.3 \mathrm{~km}$ upstream of three major water diversions and $\sim 0.8 \mathrm{~km}$ upstream of a USGS gauge station that drains a basin of $15.5 \mathrm{~km}^{2}$. There were no gauges on Iao Stream but Kinihapai Stream contributes approximately $40 \%$ of Iao Stream discharge, and Iao Stream reflects changes in Kinihapai Stream flow (see Benbow et al. 1997 and Benbow 1999). Kinihapai Stream is a stair-step sequence of riffle, run, waterfall, and pool habitats, and is characterized by a stochastic flow regime with highest flows typically occurring during the wet season from October - April. Cascades in the study reach were $<2 \mathrm{~m}$ high and defined by constricted flow over large boulders. The substrata of cascades and splash zones (optimal habitats in this study) were colonized by $T$. torrenticola populations and characterized by a thin, dark-brown epilithic layer and little filamentous algae. See Benbow et al. (1997) and Benbow (1999) for more details regarding the study site. Table 1 shows the stream discharge statistics for each year.

\section{Microhabitat classification}

During the 1994 summer, we quantified the microflow habitat (i.e., habitat micro-scale velocity, depth, and Froude number) using a thermistor-based flow meter at $2 \mathrm{~mm}$ above T. torrenticola larvae (Benbow et al. 1997). In that study, $3^{\text {rd }}$ and $4^{\text {th }}$ instars were quantified using visual counts and benthic collections of larvae greater than about $10 \mathrm{~mm}$ total body length (see methods of Benbow et al. 1997). From these flow and density data, we have grouped microhabitats into optimal (OP) and suboptimal (SOP) classes for this study. When the sites of Benbow et al. (1997) were grouped into these two microhabitats, mean micro-scale velocity, depth and Froude number for OP were $56.7 \mathrm{~cm} . \mathrm{s}^{-1}$, $2.3 \mathrm{~cm}$, and 1.23 , and for SOP they were $31.2 \mathrm{~cm} . \mathrm{s}^{-1}$, $36.1 \mathrm{~cm}$ and 0.17 , respectively (means calculated from data in Table 1 of Benbow et al. 1997). The mean velocity of OP microhabtitats was more than $20 \mathrm{~cm} . \mathrm{s}^{-1}$ greater than SOP, that when considered with depth and acceleration due to gravity, generates critical velocities (Froude number) that are an order of magnitude greater in the optimal conditions. The OP microhabitats represent cascades, splash zones and areas of shallow, high velocity flow in areas of constricted flow between boulders or the lips of waterfalls. However, cascades and splash zones (or lips of waterfalls) were not prac- 
Table 1. Mean daily discharge ( $\mathrm{Q}$ in $\left.\mathrm{m}^{3} \cdot \mathrm{sec}^{-1}\right)$ characteristics for Kinihapai Stream, Maui, Hawaii between study years. The1993 and 1994 water years represent values from October 1, 1993 and 1994 - September 30, 1994 and 1995, respectively. SD = standard deviation, $\mathrm{CV}=$ coefficient of variation.

\begin{tabular}{lcccc}
\hline & \multicolumn{2}{c}{ Water Year } & \multicolumn{2}{c}{ Study Period } \\
\cline { 2 - 5 } & 1993 & 1994 & 1994 & 1995 \\
\hline Mean & 2.66 & 1.62 & 2.9 & 1.8 \\
SD & 2.72 & 1.56 & 2.43 & 1.61 \\
CV & 1.02 & 0.96 & 0.84 & 0.9 \\
Range & $0.28-22.8$ & $0.48-11.4$ & $0.65-12.0$ & $0.48-7.47$ \\
Days with $Q>2 X$ mean & 38 & 42 & 9 & 8 \\
\hline
\end{tabular}

tically sampled for quantitative measurements of flow or larval densities. Suboptimal microhabitats were areas of riffle-like flow of moderate velocities and variable depth, which appeared to be well oxygenated. Larvae were restricted to areas of adequate flow velocity (the lower end velocities represented by the 1994 SOP sites ; Benbow et al. 1997), and were not found in pool or run habitats. Although micro-scale flow velocities were not measured in 1995, flow was observed to be consistent with 1994 optimal microhabitats, only more shallow (Tables 2 and 3 ).

\section{Benthic collections}

Larval collections were made throughout the summers of 1994 (14 sampling dates between 30 May 14 August) and 1995 (10 sampling dates between 7 May - 23 August) using benthic scouring methods (using a net with $320 \mu \mathrm{m}$ mesh) described by Benbow et al. (1997). In 1994, both OP and SOP microhabitats were sampled while only OP were sampled in 1995. It was not practical to take SOP benthic samples in 1995 due to a substantial reduction in $T$. torrenticola larval habitat and associated populations (Benbow 1999). Thus, effort was concentrated on increasing sample size in OP microhabitats from 3 samples per day in each habitat (both SOP and OP ; N = 3 each) of 1994 to 12 samples per day in OP microhabitats of $1995(\mathrm{~N}=$ 12). In addition, the study reach was increased from $50 \mathrm{~m}$ in 1994 to $200 \mathrm{~m}$ in 1995, in an effort to find colonized substrates suitable for quantitative benthic collections. Although we did not quantify the relative areas of OP vs. SOP microhabitats of the stream reach, it was apparent that both microhabitats were nearly equally represented for potential colonization. In these high gradient mountain streams, cascades and areas of torrential, constricted flow are abundant. Benthic collections were staggered among the sites such that no site was sequentially sampled more frequently than on- ce every seven weeks (see Benbow et al. 1997). Stream water temperature measurements were made on most sampling dates from the same location in the study reach using a hand thermometer.

\section{Laboratory Analysis}

Larval headcapsule width ( $\mathrm{HW}$, in $\mathrm{mm}$ ) measurements have been used to determine instar stage of chironomids in many studies (e.g., Berg \& Hellenthal 1992, Benke 1996), and Prat \& Rieradevall (1995) used both headcapsule width and length for chironomid instar discrimination. Thus, we determined instar stage using HW; however, because the larval body becomes curved after preservation, it was necessary to decapitate individuals in order to measure HW. In order to facilitate instar separation based on HW, we generated a linear regression model using headcapsule width on headcapsule length (HL, in $\mathrm{mm}$ ). It was not necessary to decapitate each larva for an accurate measure of HL, which was used to predict HW. Of 1,358 larvae collected in 1994, HW and HL measurements were made on a sub-sample of 556 (41\% of total) for the regression (Fig. 2). We used HW (or a predicted HW from the linear regression) in order to make these results more comparable to most studies of chironomid phenology (Berg \& Hellenthal 1992, Benke 1996).

Density was calculated by dividing the total number of each instar or pupae by the area sampled for each sampling date ; hereafter, sampling date density refers to the value calculated from all samples on a particular date. The mean $( \pm \mathrm{SE})$ values presented in the results section and termed mean sampling date density were taken as the mean of all sampling date density values within each year or habitat (see below). Differences in mean daily discharge, site depth, mean sampling date individual instar and total larval density, among habitats and years was tested by Wilcoxon/Kruskal-Wallis 
rank sum test and a posteriori multiple comparisons using the Tukey-Kramer HSD method. Mean water temperature difference between years was tested using a Student's t-test.

\section{Results}

\section{Stream hydrology}

Kinihapai Stream is characterized by highly variable flow over short and long temporal scales (Fig. 1). Mean daily discharge for Iao Stream (representative of Kinihapai Stream) was greater in the 1993 compared to the 1994 water year (October 1993 and 1994 - September 1994 and 1995, respectively). During shorter time intervals (e.g., three months for this study) discharge variation was still relatively high with frequent spates (Fig. 1). When each water year (WY) hydrograph is plotted with the same maximum ordinate scales (i.e., $25 \mathrm{~m}^{3} . \mathrm{s}^{-1}$ ) the mean annual discharge differences are apparent ; however, the variation of 1994 water year (WY) is masked (Fig. 1). The maximum discharge value (24 March 1994) was $\sim 2 \mathrm{X}$ as great in the $1993 \mathrm{WY}$ compared to the maximum peak in the $1994 \mathrm{WY}\left(22.8\right.$ and $12.0 \mathrm{~m}^{3} \cdot \mathrm{s}^{-1}$ for $1993 \mathrm{WY}$ and 1994 WY, respectively). When 1994 WY is plotted with a maximum scale at $12.0 \mathrm{~m}^{3} . \mathrm{s}^{-1}$, the daily flow variation becomes more obvious, as shown in the inset of Fig. 1b. Discharge variation was substantial both within and between water years and reflected by consistently high coefficient of variation $(\mathrm{CV})$ values within each water year and study period (Table 1). Over the long temporal scale mean daily discharge was significantly greater in the 1993 WY when compared to the $1994 \mathrm{WY}\left(\mathrm{X}^{2}=64.07\right.$, d.f. $=1, P<0.001$; Figure 1). At shorter temporal scales, the 1994 study period mean daily discharge was $\sim 1.6 \mathrm{X}$ greater than $1995\left(X^{2}=20.65\right.$, d.f. $=1, P<0.001$; Fig. 1$)$ but the CV was smaller (Table 1). Thus, these study periods represent significantly different flow regimes experienced by $T$. torrenticola larvae over long (between years) and short (three month study period) temporal scales.

There was a significant $(\mathrm{F}=61.4$, d.f. $=2, P<0.001)$ difference in mean microhabitat depth among years and microhabitats with the suboptimal microhabitats of 1994 the deepest $(25.9 \mathrm{~cm})$ and 1995 habitats the shallowest (1.4 cm ; Tables 2 and 3). Mean water temperature was significantly $(\mathrm{t}=-4.19$, d.f. $=37$, $P<0.001)$ higher in $1995\left(21.0^{\circ} \mathrm{C}\right)$ compared to 1994 $\left(19.9^{\circ} \mathrm{C}\right)$.

\section{Instar densities and life cycle}

Instar HW ranges (mean $\pm \mathrm{SD})$ were $\leq 0.15(0.13 \pm$ $0.01) \mathrm{mm}, 0.16-0.29(0.25 \pm 0.02) \mathrm{mm}, 0.30-0.60$ $(0.48 \pm 0.06) \mathrm{mm}$ and $>0.60(0.85 \pm 0.12) \mathrm{mm}$ for $1^{\mathrm{st}}$, $2^{\text {nd }}, 3^{\text {rd }}$, and $4^{\text {th }}$, respectively (Fig. 2). Based upon these ranges there was little overlap between $3^{\text {-rd }}$ and $4^{\text {th }}$ instars in HW or HL along the regression and $4^{\text {th }}$ instars were identified as individuals with $\mathrm{HW}>0.6 \mathrm{~mm}$ (see dashed line in Fig. 2).

Larval and pupal densities are presented for each sampling date in Tables 2 and 3. Results of Wilcoxon/Kruskal-Wallis rank sums test found a significant effect of year and microhabitat on total larval density $\left(X^{2}=17.29\right.$, d.f. $\left.=2, P<0.001\right)$ with 1994 OP significantly greater than both 1995 OP and 1994 SOP, which were statistically similar in Tukey-Kramer HSD comparisons $(P>0.05)$. This was also the case for both $1^{\text {st }}\left(X^{2}=22.25\right.$, d.f. $\left.=2, P<0.001\right)$ and $2^{\text {nd }}\left(X^{2}=\right.$ 18.62 , d.f. $=2, P<0.001$ ) instars separately (multiple comparison at $P>0.05$ ). However, there was no difference in $4^{\text {th }}$ instar density among years or microhabitats $\left(X^{2}=0.332\right.$, d.f. $\left.=2, P=0.847\right)$, and $3^{\text {rd }}$ instar density in 1994 OP and 1995 OP were both significantly greater than 1994 SOP $\left(X^{2}=14.73\right.$, d.f. $=2, P<$ $0.001)$, but not different to each other $(P>0.05)$; this was also the case when $3^{\text {rd }}$ and $4^{\text {th }}$ instars were pooled, but the difference was not as great $\left(X^{2}=7.85\right.$, d.f. $=2$, $P=0.020)$.

Interpretation of size frequency histograms found several overlapping generations indicative of a multivoltine life cycle with continuous reproduction (Fig. 3). All larval instars were collected on most sampling dates and in each microhabitat. In optimal microhabitats of 1994 and 1995, pupae were collected on most sampling dates (Tables 2 and 3) ; however, pupae were only present on two sampling dates in 1994 suboptimal microhabitats (Fig. 3).

The greatest mean sampling date density of pupae occurred in 1994 OP $\left(70 . \mathrm{m}^{-2}\right)$ with 1995 OP at about half that density $\left(37 . \mathrm{m}^{-2}\right)$ and 1994 SOP with the lowest $\left(21 . \mathrm{m}^{-2}\right)$ (Tables 2 and 3 ). The sampling date ranges were quite variable in $1994 \mathrm{OP}(0$ - $231 \mathrm{pu}-$ pae. $\left.\mathrm{m}^{-2}\right)$ and 1995 OP $\left(0-89\right.$ pupae. $\left.\mathrm{m}^{-2}\right)$. The percentage of pupae relative to the $4^{\text {th }}$ instar population (the next generation of pupae) in each habitat was variable among habitats of both years, and tended to remain consistent with the density differences among microhabitats (Tables 2 and 3). In 1994 OP microhabitats, the mean sampling date pupal density made up $7.3 \%$ of the $4^{\text {th }}$ instar density, while 1995 OP and 1994 SOP had $4.5 \%$ and $2.4 \%$, respectively. Even the highest percentage of pupae $(26.3 \%)$ on any date of both years 
Table 2. Mean sampling date density (individuals. $\mathrm{m}^{-2}$ ) and habitat depth (cm) of T. torrenticola larvae and pupae in 1994 from Kinihapai Stream, Maui, Hawai'i. Habitats correspond to optimal (OP) and suboptimal (SOP) microhabitats as described in the text. The percentage of pupae (\% pupae) relative to $4^{\text {th }}$ instar density is given for each date. $\mathrm{SE}=$ Standard Error.

\begin{tabular}{|c|c|c|c|c|c|c|c|c|c|c|c|c|c|c|c|c|}
\hline \multirow{3}{*}{ Date } & & & \multicolumn{14}{|c|}{ T. torrenticola Instar and Pupal Density (individuals. $\mathrm{m}^{-2}$ ) } \\
\hline & \multicolumn{2}{|c|}{ Depth } & \multicolumn{2}{|c|}{$1^{\text {st }}$} & \multicolumn{2}{|c|}{$2^{\text {nd }}$} & \multicolumn{2}{|c|}{$3^{\mathrm{rd}}$} & \multicolumn{2}{|c|}{$4^{\text {th }}$} & \multicolumn{2}{|c|}{ Total } & \multicolumn{2}{|c|}{ Pupae } & \multicolumn{2}{|c|}{ \% Pupae } \\
\hline & OP & SOP & $\mathrm{OP}$ & SOP & $\mathrm{OP}$ & SOP & $\mathrm{OP}$ & SOP & $\mathrm{OP}$ & SOP & OP & SOP & $\mathrm{OP}$ & SOP & OP & SOP \\
\hline 31-May & 1.3 & 11.0 & 208 & 79 & 139 & 0 & 69 & 238 & 789 & 1032 & 1206 & 1349 & 101 & 0 & 12.8 & 0.0 \\
\hline 3-Jun & 6.7 & 30.3 & 653 & 150 & 287 & 139 & 176 & 139 & 713 & 851 & 1829 & 1279 & 60 & 0 & 8.4 & 0.0 \\
\hline 9-Jun & 1.8 & 27.7 & 550 & 0 & 775 & 79 & 458 & 79 & 908 & 238 & 2692 & 397 & 0 & 0 & 0.0 & 0.0 \\
\hline 11-Jun & 0.8 & 41.7 & 1019 & 0 & 683 & 135 & 347 & 0 & 718 & 772 & 2766 & 907 & 81 & 0 & 11.3 & 0.0 \\
\hline 15-Jun & 7.7 & 25.0 & 667 & 95 & 944 & 333 & 1338 & 317 & 750 & 1270 & 3699 & 2016 & 0 & 0 & 0.0 & 0.0 \\
\hline 20-Jun & 10.0 & 33.3 & 313 & 0 & 622 & 303 & 523 & 101 & 487 & 407 & 1945 & 811 & 0 & 170 & 0.0 & 41.9 \\
\hline 29-Jun & 9.3 & 30.3 & 656 & 465 & 2310 & 256 & 1743 & 427 & 774 & 432 & 5483 & 1579 & 33 & 130 & 4.3 & 30.1 \\
\hline 3-Jul & 8.3 & 25.7 & 1622 & 314 & 2547 & 774 & 1169 & 489 & 845 & 931 & 6183 & 2508 & 0 & 0 & 0.0 & 0.0 \\
\hline 10-Jul & 19.0 & 23.3 & 1066 & 302 & 2302 & 637 & 828 & 181 & 862 & 1069 & 5057 & 2188 & 0 & 0 & 0.0 & 0.0 \\
\hline 21-Jul & 13.0 & 19.0 & 1057 & 56 & 1711 & 148 & 1344 & 315 & 881 & 1315 & 4992 & 1833 & 194 & 0 & 22.0 & 0.0 \\
\hline 28-Jul & 10.0 & 22.7 & 828 & 60 & 1117 & 60 & 1481 & 329 & 1956 & 1135 & 5382 & 1583 & 145 & 0 & 7.4 & 0.0 \\
\hline 1-Aug & 18.0 & 18.7 & 254 & 139 & 901 & 218 & 409 & 827 & 1317 & 540 & 2881 & 1724 & 139 & 0 & 10.5 & 0.0 \\
\hline 7-Aug & 9.3 & 23.3 & 476 & 104 & 1292 & 399 & 764 & 503 & 1608 & 1500 & 4140 & 2506 & 0 & 0 & 0.0 & 0.0 \\
\hline 14-Aug & 3.7 & 30.0 & 1782 & 0 & 2569 & 333 & 1736 & 315 & 880 & 852 & 6968 & 1500 & 231 & 0 & 26.3 & 0.0 \\
\hline Mean & 8.5 & 25.9 & 796 & 126 & 1300 & 272 & 885 & 304 & 963 & 882 & 3944 & 1584 & 70 & 21 & 7.3 & 2.4 \\
\hline $\mathrm{SE}$ & 1.5 & 2.0 & 127 & 38 & 224 & 58 & 154 & 57 & 106 & 100 & 59 & 46 & 90 & 85 & (a) & (a) \\
\hline
\end{tabular}

(a) The mean for $\%$ pupae was calculated as the mean pupal density/mean 4th instar density, and not for \% pupae over all sampling dates because there were only two dates in 1994 SOP where pupae were collected.

Table 3. Mean sampling date density (individuals. $\mathrm{m}^{-2}$ ) and habitat depth $(\mathrm{cm})$ of $T$. torrenticola larvae and pupae in 1995 from Kinihapai Stream, Maui, Hawaii. Habitats correspond to optimal (OP) and suboptimal (SOP) microhabitats as described in the text. The percentage of pupae (\% pupae) relative to $4^{\text {th }}$ instar density is given for each date. SE $=$ Standard Error.

\begin{tabular}{|c|c|c|c|c|c|c|c|c|}
\hline \multirow[b]{2}{*}{ Date } & \multirow[b]{2}{*}{ Depth } & \multicolumn{7}{|c|}{ T. torrenticola Instar and Pupal Density (individuals. $\mathrm{m}^{-2}$ ) } \\
\hline & & $1^{\text {st }}$ & $2^{\text {nd }}$ & $3^{\text {rd }}$ & $4^{\text {th }}$ & Total & Pupae & \% Pupae \\
\hline 26-May & 1.9 & 241 & 790 & 1047 & 778 & 2855 & 33 & 4.2 \\
\hline 30-May & 2.0 & 249 & 590 & 1062 & 909 & 2810 & 81 & 9.0 \\
\hline 5-Jun & 1.2 & 101 & 366 & 448 & 873 & 1788 & 0 & 0.0 \\
\hline 13-Jun & 1.5 & 17 & 558 & 559 & 711 & 1846 & 23 & 3.3 \\
\hline 16-Jun & 1.3 & 155 & 871 & 1024 & 793 & 2844 & 89 & 11.3 \\
\hline 21-Jun & 1.2 & 209 & 570 & 955 & 970 & 2704 & 20 & 2.0 \\
\hline 26-Jun & 1.0 & 241 & 790 & 1047 & 778 & 2855 & 33 & 4.2 \\
\hline 1-Jul & 0.5 & 56 & 758 & 577 & 837 & 2228 & 30 & 3.6 \\
\hline 7-Jul & 2.2 & 67 & 377 & 828 & 899 & 2171 & 43 & 4.8 \\
\hline 13-Jul & 1.6 & 265 & 374 & 604 & 727 & 1970 & 19 & 2.5 \\
\hline Mean & 1.4 & 160 & 604 & 815 & 827 & 2407 & 37 & 4.5 \\
\hline SE & 0.2 & 29 & 61 & 77 & 27 & 19 & 34 & 0.3 \\
\hline
\end{tabular}



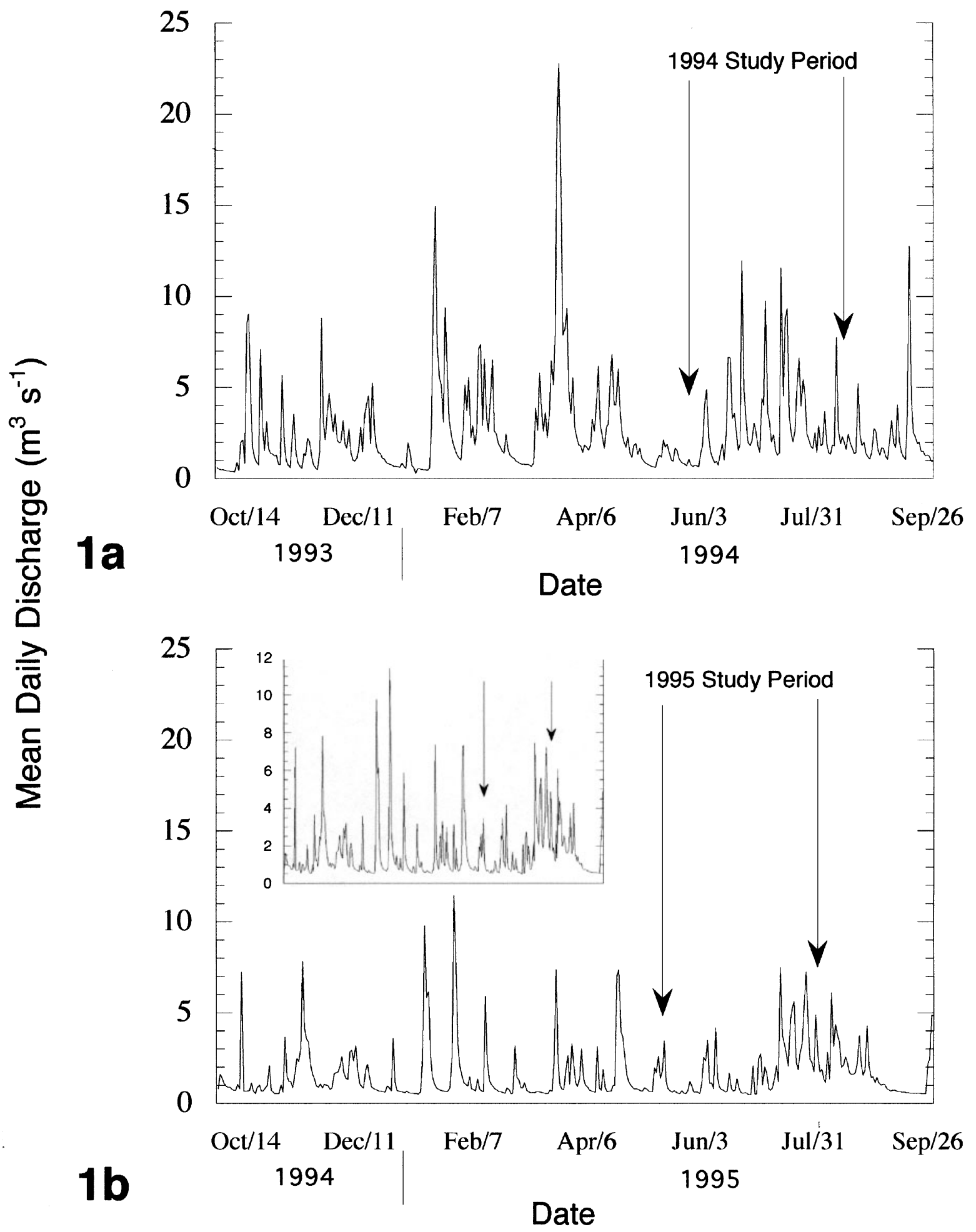

Fig. 1. Iao Stream, Maui, Hawaii hydrographs for water years 1993 and 1994 (1a and 1b, respectively). Iao Stream mean daily discharge was used to assess Kinihapai Stream hydrology (Benbow et al. 1997). Note the ordinate axis scales. The inset hydrograph in $1 b$ shows discharge variation when plotted with a maximum ordinate axis value of $12 \mathrm{~m}^{3}$. $\mathrm{sec}^{-1}$ corresponding to the peak flow day of that water year. 
(1994 OP : 14 August) was only about one quarter of the $4^{\text {th }}$ instar larval population.

All instars were present throughout both study periods ; however, $1^{\text {st }}$ and $2^{\text {nd }}$ instar densities were relatively less abundant on most sampling dates in 1994 SOP habitats and 1995 OP microhabitats. Early instars are undoubtedly underrepresented due to the coarse net mesh size $(320 \mu \mathrm{m})$ used ; however, this error is consistent among years and habitats. The short duration of the early instars may also be an important factor affecting $1^{\text {st }}$ instar representation. In 1994 OP microhabitats, $1^{\text {st }}$ and $2^{\text {nd }}$ instars made up substantial proportions of the total larval communities, if not the greatest percentage on a few dates (Fig. 3). Life cycle studies normally report greatest abundance of $1^{\text {st }}$ instars with subsequent, sequential density decreases through to the adult stage (Benke 1998). This was only the case on some dates in OP microhabitats of 1994, once in the 1994 SOP and never in 1995 OP microhabitats (Figure 3 ). The lower $1^{\text {st }}$ instar proportions on sampling dates in 1994 SOP and 1995 OP microhabitats compared to 1994 OP suggests that larvae were consistently less abundant in the suboptimal microhabitats of 1994 and optimal microhabitats of 1995. The significantly lower $1^{\text {st }}$ instar densities corroborate the proportion data. Thus, early instars are both lower in density and make up a relatively smaller proportion of the larval population in suboptimal microhabitats. Conversely, $4^{\text {th }}$ instar density was not significantly different among habitats, and almost always made up the greatest proportion of the total larval population in 1994 SOP and 1995 OP microhabitats (Fig. 3). Since the same methods and net sizes were used for all samples, sampling bias is not suspected to reflect these results. Rather, the data show that there is habitat segregation among the early and late instars of $T$. torrenticola.

In terms of instar proportions, 1995 OP populations reflect a larval size class structure that is intermediate between optimal and suboptimal microhabitats of 1994. When compared to 1994 SOP, 1995 OP microhabitats show more equal proportions among the $2^{\text {nd }}$, $3^{\text {rd }}$, and $4^{\text {th }}$ instars, which is similar to 1994 OP ; however, 1995 OP also had a much smaller proportion, and lower density, of $1^{\text {st }}$ instars on all sampling dates, which is more similar to 1994 SOP. In 1995, T. torrenticola microhabitats had flow and depth characteristics were similar to 1994 OP, but 1995 water temperatures were significantly higher. Thus, there was much less overall suitable habitat available in 1995 (we could not find comparable suboptimal sites in 1995), which may have acted to concentrate all instars into the same ha-

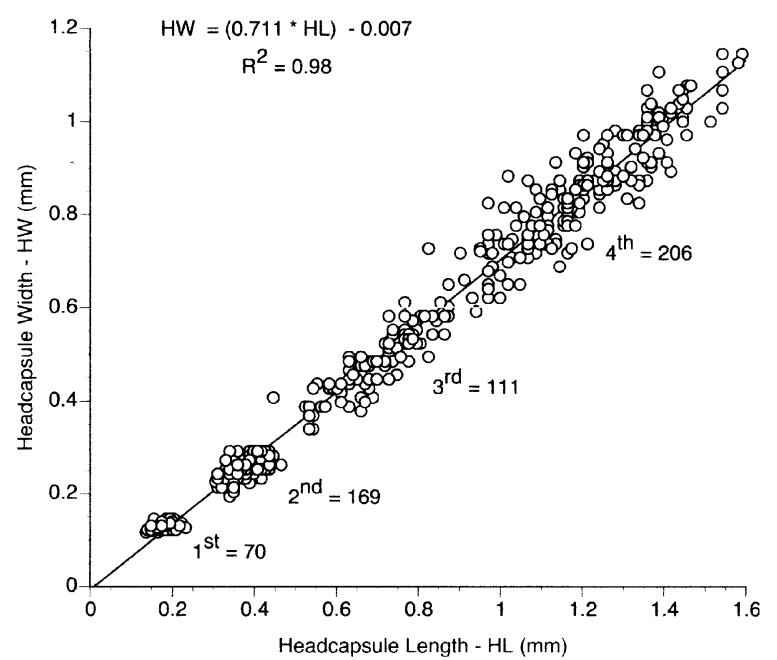

Fig. 2. Individual larval headcapsule length and width regression for Telmatogeton torrenticola from Kinihapai Stream, Maui, Hawaii. This regression was used for predicting headcapsule width from length in order to facilitate sample processing.

bitat. In 1994, the larger instars were more equally distributed between the optimal and suboptimal habitat classes (Fig. 3).

Relative total larval densities were consistently higher in 1994 OP when compared to 1994 SOP and 1995 OP (Fig. 3 ; darker and lighter indicate relatively higher and lower densities, respectively; among years and microhabitats). Although not comprehensively evaluated in this study, spate (S) and high water events (*) are indicated on each size frequency histogram for qualitative comparisons of these events on total instar density changes over time. Typically following a spate or high water event, larval densities were relatively lower, or unchanged, on the subsequent sampling date (Figure 3). The time between water events and the next sampling date appeared to be important for noticeable density changes, where the longer the time since the event the less likely for a relative density decrease (or sometimes a slight increase) (Fig. 3). After the second spate in 1994 there was a relative density increase in both optimal and suboptimal habitats on the next sampling date; however, there was a long time interval between that event and the subsequent sampling date (Fig. 3).

\section{Discussion}

In this study we have documented the larval instar 


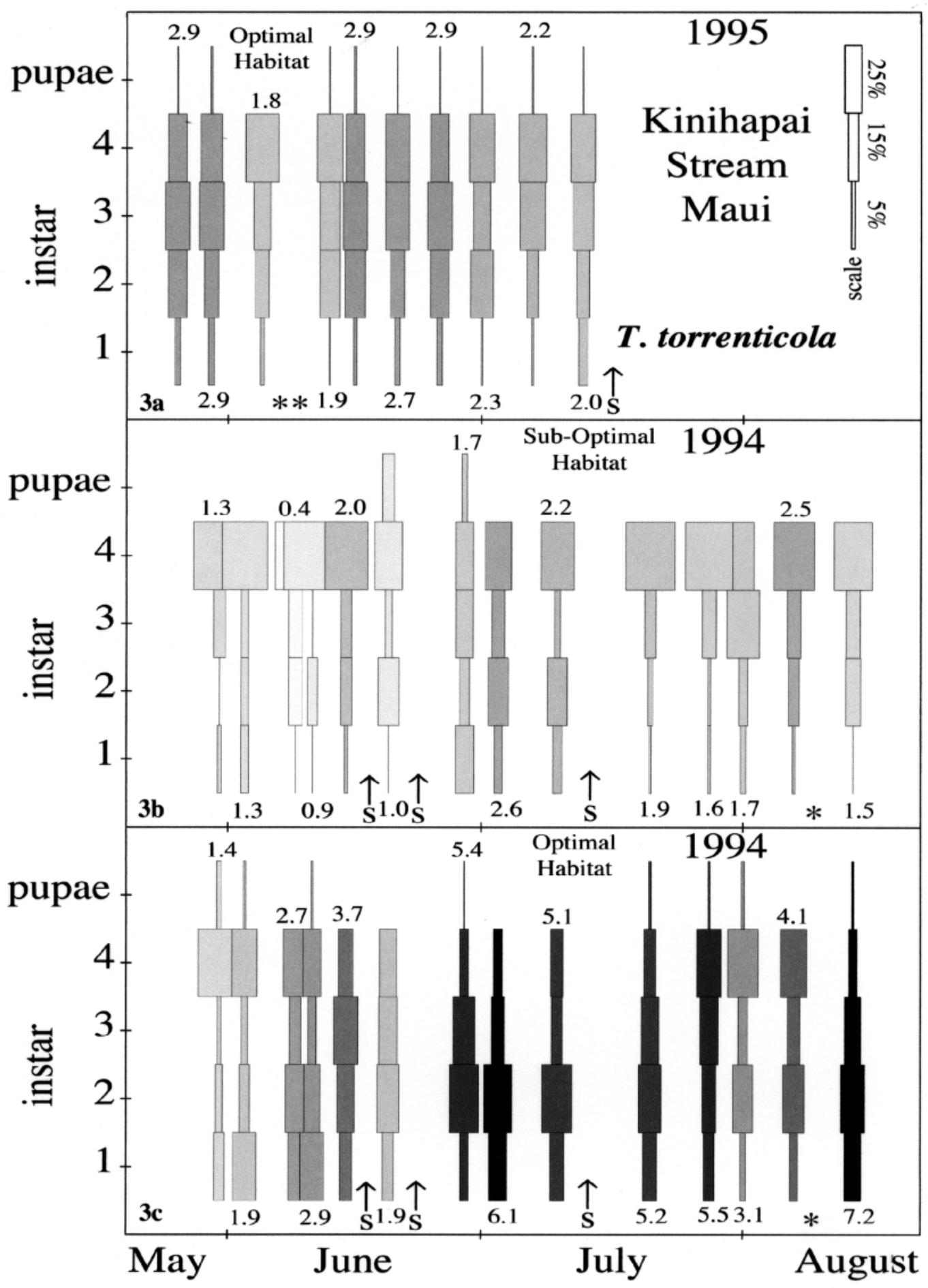

Fig. 3. Instar and pupal (life stage) frequency as histogram percent (100\% for all stages on a sampling date) of Telmatogeton torrenticola in relation to sampling date (expressed as Julian date) for 1995 optimal (3a), 1994 suboptimal (3b) and 1994 optimal habitats (3c) within Kinihapai Stream, Maui, Hawaii. Numbers at the top or bottom of each frequency histogram represent the total instar density X1000. The shading of histograms represents relative density difference between years and microhabitats where the darkest and lightest indicate the higher and lower densities, respectively. Spates (S) and high water events $(*)$ are indicated during the study period. 
densities and life cycle of Telmatogeton torrenticola from Kinihapai Stream, Maui, Hawaii. There are few Chironomidae life cycle studies from tropical regions of the world (Jackson \& Sweeney 1995), except for a few studies outside of Hawaii (Ferrington et al., 1993), and several that included Chironomidae in analyses (but not as a focus) from neotropical streams of Costa Rica by Ramirez and Pringle (1998 a,b), Ramirez and Pringle (2001), Rosemond et al. (1998, 2001) and Benstead (1996). This study provides life cycle information on a tropical freshwater stream insect, and more particularly, quantitative ecology of the larval populations of an endemic Hawaiian midge. With the freshwater Telmatogeton species of Hawaii representing the only freshwater populations of the subfamily Telmatogetoninae, these data are particularly unique, since the more common marine relatives are found throughout the world (Cranston 1995).

The significant difference in stream discharge of Kinihapai Stream between two summers contributed to a loss of colonizable habitat for T. torrenticola, and significantly reduced larval populations in cascade and torrenticolous habitats. These flow differences also had an effect on inter-instar densities and proportions between years and among two microhabitats defined by flow, indicating that stream flow over both the long (between two years) and short term had an effect on the life cycle of $T$. torrenticola.

This Hawaiian stream midge has a multivoltine, asynchronous life cycle with continuous reproduction, which is common among Chironomidae (Oliver 1971, Butler 1984, Pinder 1986) including Puerto Rico (Ferrington et al. 1993), and intertidal species in British Columbia (Morley \& Ring 1972), among many others (see Tokeshi 1995); however, the marine intertidal Telmatogeton japonicus Tokunaga from Japan is only thought to have two generations per year (Tokunaga 1935). Other Chironomidae species can exhibit much longer life cycles (i.e., univoltine, semivoltine or merovoltine ; Tokeshi, 1995), with one extreme being one generation every seven years reported for two Chironomus species from Alaska (Butler 1982). Our results are also consistent with the only other published aquatic insect life cycle study from Hawai'i, which documented a multivoltine life cycle and continuous reproduction for the introduced caddisfly, Cheumatopsyche pettiti (Kondratieff et al. 1997).

The data presented here were evaluated in optimal (OP) and suboptimal (SOP) microhabitats within the summer of 1994 and OP microhabitats of 1995. The mean daily discharge of the 1995 study period was significantly reduced by $40 \%$ of 1994 , and also corres- ponded with significantly higher temperatures. Overall total instar density was significantly higher in 1994 OP followed sequentially by 1995 OP and 1994 SOP with lower densities. First and $2^{\text {nd }}$ instar densities (not the proportion of early instars to the total larval population) followed the same pattern, but this was not the case with 1994 OP or 1995 OP $3^{\text {rd }}$ and $4^{\text {th }}$ instars, separately or pooled, which were both significantly greater than 1994 SOP, but not different from each other. The reduction in stream discharge reduces areas of shallow, high velocity and cascading flow and splash zones, the primary microhabitats of T. torrenticola larvae (Benbow et al. 1997). We suggest that the lower discharge of 1995 severely reduced the amount of suitable habitat for larval colonization. This was reflected in our need to increase the study reach (from $50 \mathrm{~m}$ to $200 \mathrm{~m}$ ) in order to locate appropriate substrate with torrential flow colonized by $T$. torrenticola. Increased water temperatures might have also changed the epilithic food quality of OP habitats, but with only a $1.1^{\circ} \mathrm{C}$ difference this seems unlikely. However, temperature and food quality influence chironomid life cycles (Butler 1982, Tokeshi 1995), and probably contributed to the lower 1994 SOP and 1995 OP densities.

We suspect that food quality may have been the limiting resource in 1994 SOP and 1995 OP habitats, affecting early instar generation time and persistence. Stream flow is known to have significant effects on epilithic community structure (Biggs \& Close 1989, Dodds 1991, Biggs \& Thomsen 1995, Nikora et al. 1998), which is the primary food resource of grazing chironomids such as T. torrenticola. Temperature and flow may have played a role in the lower 1994 SOP and 1995 OP densities directly by effects on insect metabolism (Butler 1982), and/or by modifying the epilithic food resources. In this study, it appears that SOP microhabitats in a year of 'normal' flow were comparable to OP microhabitats during a year of significantly reduced stream discharge (1995).

In many studies, aquatic insect density proportions typically decrease with later instars (i.e., densities of $\left.1^{\text {st }}>2^{\text {nd }}>3^{\text {rd }}>4^{\text {th }}\right)($ Benke $1984,1996,1998)$. It has been found that density is negatively correlated with body size (Strayer 1994), so it is expected that $1^{\text {st }}$ instars should be relatively more abundant than later instars in a multivoltine life cycle. The lack of $T$. torrenticola conformity to this expectation is probably explained by 1) losses of $1^{\text {st }}$ instars during sampling and 2) inter-instar habitat discrimination based upon larval space competition and agonistic behavior. A third explanation might be that the short duration of the early instars made sampling them difficult throughout the 
study. We undoubtedly lost most first instars due to coarse mesh size ; however, this was consistent between years and habitat, thus, changes should not reflect sampling bias. Also, numerous observations of intraspecific competition among the larger larvae were made in both study years (MEB, personal observations). When a grazing larva touched another larva there was usually a brief period $(5-10 \mathrm{~s})$ of attacks until one retreated into its case or was dislodged from the substrate. Agonistic behavior has been reported in Telmatogeton $(=$ Paraclunio Saunders) alaskensis Coquillett and T. trilobatus Kieffer, two marine chironomids that occupy the spash zones of intertidal rocky shores (Robles 1984). Robles (1984) reported that these Telmatogeton aggressively defend silken tubes, and that the tube dispersion is usually uniform, probably a result of the agonistic behavior. Could larger $T$. torrenticola instars have been displacing smaller instars in this study ? This question needs further investigation.

Although pupae were collected over the course of each study period, densities were not great enough to accurately evaluate discrete emergence patterns. The absence of higher pupal densities, and corresponding higher proportions of the $4^{\text {th }}$ instars may, 1) represent single generations entering metamorphosis prior to emergence, 2) increased pupal mortality, or 3) show that only a small fraction of pupae remain in the larval habitat for metamorphosis, since the larval size frequency histograms indicate multiple overlapping generations. Thus, the pupae probably represent overlapping generations, and the low pupal percentages relative to the $4^{\text {th }}$ instar population (which also shows overlapping generations) indicate increased predation of pupae, physical dislodgement by $4^{\text {th }}$ instars, or intentional late $4^{\text {th }}$ instar drift to downstream sites for pupal metamorphosis (a possible life history adaptation to ensure successful emergence).

Because Kinihapai Stream is enclosed by two mountain ridges, and $T$. torrenticola is a flightless midge (Wirth 1947), the only source of upstream recruitment must be that due to active upstream movement by adults. Indeed, adult upstream movement has been reported for other stream insects (Winterbourn \& Crowe 2001), and has been proposed to be of selective advantage for most stream insects (Anholt 1995). If the majority of adults (or pupae) were continuously swept substantial distances downstream, larval populations would systematically be removed from upstream habitat without upstream migration and/or long-lived adults. The former is supported by laboratory studies (MEB unpublished data) showing that adults do not have a gut, thus, they do not feed as adults, and proba- bly only have a 24 - $36 \mathrm{~h}$ adult existence, similar to the conspecific T. japonicus (Tokunaga 1935 ; Williams 1944) and other flightless chironomids found elsewhere (Pinder 1986). Adult T. torrenticola have been commonly observed to scamper along the banks in small swarms or individually (Wirth 1947). We suggest that the non-feeding adults migrate upstream along the banks during their temporary terrestrial existence. Intentional $4^{\text {th }}$ instar drifting to habitats of slower, but well oxygenated flow would increase the probability of successful emergence and adult existence, supporting continuous upstream recruitment.

\section{Conclusions}

In conclusion, this study is the first to document the life cycle of any midge in the Hawaiian Islands. Telmatogeton torrenticola has a multivoltine, asynchronous life cycle and continuous reproduction that is affected by long-term stream flow and microhabitat conditions. These data raise new questions concerning the role of microhabitat flow quality and life cycle parameters within a spatially and temporally heterogenous fluvial environment. Quantitative data on the life cycle of this torrenticolous midge, among different years and microhabitats, provides important information for understanding the Telmatogeton genera of the Hawaiian Islands. These populations represent an evolutionary reinvasion of freshwater from a marine existence, and we suggest that $T$. torrenticola and other Hawaiian Telmatogeton species could be used to empirically test hypotheses concerning life history adaptations and other evolutionary strategies allowing for intertidal marine insect invasion into freshwater lotic habitats. The data in this study are useful for a better understanding of the ecological and evolutionary patterns of the endemic freshwater chironomids of Hawaii.

\footnotetext{
Acknowledgments

Mike Lee is gratefully acknowledged for his enthusiastic support of this research over the past several years. We would also like to thank S. Hau and W. Puleloa who provided valuable field assistance and hospitality throughout the course of this study. K. Thorn and J. Neal provided logistical and moral support on very long days in the field throughout the 1995 study period. M. McIntosh provided valuable comments on an earlier version of this manuscript. Two anonymous reviewers greatly improved this paper. This research would not have been possible without financial support provided by the U.S. Army Corps of Engineers, Honolulu District, Ft. Shafter, Hawaii, Mike Coleman with the USDA Natural Resources Conservation Service, Honolulu, Hawaii, the Department of Biology, Research Institute, and a Graduate Student Fellowship at the University of Dayton, Dayton, Ohio.
} 


\section{References}

Anholt B.R. 1995. - Density dependence resolves the stream drift paradox. Ecology, 76, 2235-2239.

Benbow M.E. 1999. - Natural history and bioenergetics of an endemic Hawaiian chironomid : fluctuating stability in a stochastic environment. Dissertation, University of Dayton, Dayton, $\mathrm{OH}$.

Benbow M.E., Burky A.J., \& Way C.M. 1997. — Larval habitat preference of the endemic Hawaiian midge, Telmatogeton torrenticola Terry (Telmatogetoninae). Hydrobiologia, 346, 129-136.

Benke A.C. 1984. - Secondary production of aquatic insects. Pages 289-322 in The Ecology of Aquatic Insects. Resh V.H. \& Rosenberg D.M. (Eds). Praeger Publishers, New York.

Benke A.C. 1996. - Secondary production of macroinvertebrates. Pages 557-578 in Methods in Stream Ecology. Hauer F.R. \& Lamberti G.A. (Eds)., Academic Press, New York.

Benke A.C. 1998. — Production dynamics of riverine chironomids : extremely high biomass turnover rates of primary consumers. Ecology, 79, 899-910

Benstead J.P. 1996. - Macroinvertebrates and the processing of leaf litter in a tropical stream. Biotropica, 28, 367-375.

Berg M.B. \& Hellenthal R.A. 1992. — Life histories and growth of lotic chironomids (Diptera : Chironomidae). Ann. Entomol. Soc. Am., 85, 578-589.

Biggs B.J.F. \& Close M.E. 1989. — Periphyton biomass dynamics in gravel bed rivers : the relative effects of flows and nutrients. Freshwat. Biol., 22, 209-231.

Biggs B.J.F. \& Thomsen H.A. 1995. - Disturbance of stream periphyton by perturbations in shear stress time to structural failure and differences in community resistance. J. Phycol., 31, 233-241.

Butler M.G. 1982. - A 7-year life cycle for two Chironomus species in arctic Alaskan tundra ponds (Diptera : Chironomidae). Can. J. Zool., 60, 58-70.

Butler M.G. 1984. - Life histories of aquatic insects. Pages 24-55 in The Ecology of Aquatic Insects. Resh V.H. \& Rosenberg D.M (Eds). Praeger Publishers, New York.

Chubb A.L., Zink R.M., \& Fitzsimons J.M. 1998. - Patterns of mtDNA variation in Hawaiian freshwater fishes : the phylogenetic consequences of ampidromy. J. Hered., 89, 8-16.

Cranston P.S. 1995. - Systematics. Pages 31-61 in The Chironomidae : The biology and ecology of non-biting midges. Armitage P., Cranston P.S., \& Pinder L.C.V. (Eds). Chapman and Hall, London.

Dodds W.K. 1991. — Micro-environmental characteristics of filamentous algal communities in flowing freshwaters. Freshwat. Biol., 25, 199-209.

Englund R.A. 1998. - Response of the orangeblack Hawaiian damselfly (Megalagrion xanthomelas), a Candidate Threatened Species, to increases in stream flow. Bishop Mus. Occ. Pap., 56, 19-24.

Englund R.A. 1999. - The impacts of introduced poeciliid fish and Odonata on the endemic Megalagrion (Odonata) damselflies of Oahu Island, Hawai'i. J. Insect Conserv., 3, 225-243.

Englund R.A. 2002. - The loss of native biodiversity and continuing nonindigenous species introductions in freshwater, estuarine, and wetland communities of Pearl Harbor, Oahu, Hawaiian Islands. Estuaries, 25, 418-430.

Englund R.A \& Polhemus D.A. 2001. — Evaluating the effects of introduced rainbow trout (Oncorhynchus mykiss) on native stream insects on Kauai Island, Hawaii. J. Insect Conserv., 5, 265-281.

Ferrington L.C. Jr., Buzby K.M., \& Masteller E.C. 1993. - Composition and temporal abundance of Chironomidae emergence from a tropical rainforest stream at El Verde, Puerto Rico. J. Kansas Entomol. Soc., 66, 167-180.
Jackson J.K. \& Sweeney B.W. 1995. — Present status and future directions of tropical stream research. J. N Am. Benthol. Soc., 14, 5-11.

Kondratieff B.C., Bishop R.J., \& Brasher A.M. 1997. - The life cycle of an introduced caddisfly, Cheumatopsyche pettiti (Banks) (Trichoptera : Hydropsychidae) in Waikolu Stream, Molokai, Hawaii. Hydrobiologia, 350, 81-85.

Liebher J.K. \& Polhemus D.A. 1997. — R.C.L. Perkins : 100 years of Hawaiian entomology. Pac. Sci., 51, 343-355.

McIntosh M.D., Benbow M.E., Burky A.J. 2002. — Effects of stream diversion on riffle macroinvertebrate communities in a Maui, Hawaii, stream. Riv. Res. Appl., 18, 569-581.

Morley R.L. \& Ring R.A. 1972. - The intertidal chironomidae (Diptera) of British Columbia II. Life history and population dynamics. Can. Ent., 104, 1099-1121.

Newman L.J. 1977. - Chromosomal evolution of the Hawaiian Telmatogeton (Chironomidae, Diptera). Chromosoma, 64, 349-369.

Newman L.J. 1988. - Evolutionary relationships of the Hawaiian and North American Telmatogeton (Insecta ; Diptera : Chironomidae). Pac. Sci., 42, 56-64.

Nikora V.I., Suren A.M., Brown S.L.R., \& Biggs B.J.F. 1998. — The effects of the moss Fissidens rigidulus (Fissidentaceae : Musci) on near-bed flow structure in an experimental cobble bed flume. Limnol. Oceanogr., 43, 1321-1331.

Oliver D.R. 1971. - Life history of the chironomidae. Ann. Rev. Entomol., 16, 211-230.

Pinder L.C.V. 1986. - Biology of freshwater Chironomidae. Ann. Rev. Entomol., 31, 1-23.

Polhemus D.A. 1997. - Phylogenetic analysis of the Hawaiian damselfly genus Megalagrion (Odonata : Coenagrionidae) : implications for biogeography, ecology, and conservation biology. Pac. Sci., 51, 395-412.

Polhemus D.A \& Asquith A. 1996. - Hawaiian Damselflies : A Field Identification Guide. Bishop Museum Press, Honolulu. $122 \mathrm{p}$.

Prat, N. \& Rieradevall M. 1995. — Life cycle and production of Chironomidae (Diptera) from Lake Banyoles (NE Spain). Freshwat. Biol., 33, 511-524.

Ramirez A. \& Pringle C.M. 1998a. — Invertebrate drift and benthic community dynamics in a lowland neotropical stream, Costa Rica. Hydrobiologia, 386, 1-3.

Ramirez A \& Pringle C.M. 1998b. - Structure and production of a benthic insect assemblage in a neotropical stream. J. N. Am. Benthol. Soc., 17, 443-463.

Ramirez A. \& Pringle C.M. 2001. - Spatial and temporal patterns of invertebrate drift in streams draining a Neotropical landscape. Freshwat. Biol., 46, 47-62.

Robles L. 1984. - Coincidence of agonistic larval behaviour, uniform dispersion, and unusual pupal morphology in a genus of marine midges (Diptera : Chironomidae). J. Nat. Hist., 18, 897-904.

Rosemond A.D., Pringle C.M., \& Ramirez A. 1998. - Macroconsumer effects on insect detritivores and detritus processing in a tropical stream. Freshwat. Biol., 39, 515-523.

Rosemond A.D., Pringle C.M., \& Ramirez A. 2001. - A test of topdown and bottom-up control in a detritus-based food web. Ecology, 82, 2279-2293.

Strayer D.L. 1994. - Body size and abundance of benthic animals in Mirror Lake, New Hampshire. Freshwat. Biol., 32, 83-90.

Tokeshi M. 1995. - Life cycles and population dynamics. Pages 225-268 in Armitage P., \& Cranston P. S. (Eds). The Chironomidae : The biology and ecology of non-biting midges. Chapman and Hall, London

Tokunaga M. 1935. - Chironomidae from Japan (Diptera), IV. The early stages of a marine midge, Telmatogeton japonicus Tokunaga. Philipp. J. Sci., 57, 491-511. 
Williams F.X. 1944. - Biological studies in Hawaiian water-loving insects. Part III. Diptera or flies D. Culicidae, Chironomidae, and Ceratopogonidae. Proc. Haw. Ent. Soc., 12, 166-169.

Winterbourn M.J. \& Crowe A.L.M. 2001. — Flight activity of insects along a mountain stream : is directional flight adaptive? Freshwat. Biol., 46, 1479-1489.

Wirth W.W. 1947. - A review of the genus Telmatogeton Schiner, with descriptions of three new Hawaiian species (Diptera : Tendipedidae). Proc. Haw. Ent. Soc., 13, 143-191.
Wolff R.H., Brasher A.M., \& Richards A.B. 2002. — New generic records of Hawaiian Chironomidae (Diptera). Bishop Mus. Occ. Pap., 69, 31-33.

Zimmerman E.C. 2001. — Insects of Hawai'i. Volume 1 : Introduction with a new preface and dedication. Originally published in 1947. University of Hawai'i Press, Honolulu.

Zink R.M., Fitzsimons J.M., Dittmann D.L., Reynolds D.R., \& Nishimoto R.T. - 1996. Evolutionary genetics of Hawaiian freshwater fish. Copeia, 2, 330-335. 